\title{
Transaction costs and fisheries co-management
}

\begin{abstract}
Fisheries co-management as an alternative to centralized command and control fisheries management is often suggested as a solution to the problems of fisheries resource use conflicts and overexploitation. This paper highlights some elements of the transaction costs under a fisheries co-management system. The transaction costs can be categorized into three major cost items: (i) information costs, (ii) collective fisheries decision-making costs, and (iii) collective operational costs. An approach to measuring transaction costs of fisheries comanagement systems both in static and dynamic processes is also proposed. There is a need to empirically evaluate the nature of the transaction costs involved in fisheries comanagement institutions as a basis for evaluating the efficiency or net benefits of co-managed fisheries compared to centrally managed fisheries.
\end{abstract}

Keyword: Collective fisheries decision-making costs; Collective operational costs; Fisheries co-management; Information costs; Institutions; Transaction costs 